\title{
Preterm Delivery and Growth Restriction in Multifetal Pregnancies reduced to Twins: Case-Control Series
}

\author{
${ }^{1}$ Anuradha R Shewale, ${ }^{2}$ Bhavana Shewale
}

\begin{abstract}
An adverse consequence of the widespread introduction of assisted reproductive techniques has been an exponential increase in the prevalence of multifetal pregnancies (Botting et al 1987). Such pregnancies are associated with increased risk of miscarriage and perinatal death (Kiely et al 1992). One of the options in the management of multifetal pregnancies is embryo reduction to twins which is associated with a reduction in the background risk of adverse pregnancy outcome (Evans et al 1995). The aim of the study was to compare the gestation at delivery and birth weight of surviving twins following multifetal pregnancy reduction to those in a control group of dichorionic non-reduced twins.
\end{abstract}

Materials and methods: A case control study evaluating pregnancy outcomes post embryo reduction. Study takes into account all patients with successful day three embryo transfers resulting in multifetal pregnancy. First trimester embryo reduction was carried out by intracardiac injection of $\mathrm{KCl}$.

Results: A total of 26 multifetal pregnancies were reduced to twins at early gestational age (7-9 weeks). Two cases $(7.6 \%)$ of miscarriage, no cases of chorioamnionitis and five cases (19.2\%) of transient spotting were recorded as postoperative complications. There was no vanishing of embryos in those reduced to twins. A total of 24 patients $(92.3 \%)$ with twin pregnancies took home at least one baby, while $18(69.23 \%)$ of these took both babies home. This was analyzed and compared with a control group of women with nonreduced twins pregnancies.

The preterm delivery rate (defined as fetuses delivered before 37 weeks) in twin pregnancies was $53.8 \%(n=14)$, with a severe preterm rate (defined as fetuses delivered before 32 weeks) of $23.07 \%(n=6)$. One case $(1.92 \%)$ of stillbirth occurred. The perinatal mortality rate was $13.46 \%$ ( $n=6$ newborns, and a 33-week stillbirth), mainly due to severe preterm labor. The latter group included no registered cases of newborns with congenital malformations. A total of 24 patients $(92.3 \%)$ with twin pregnancies took home at least one baby, while 18 $(69.23 \%)$ of these took both babies home.

In two of the 26 multifetal pregnancies reduced to twins there was miscarriage of both fetuses before 24 weeks of gestation the median interval between reduction and multifetal loss was 5 weeks.

In pregnancy reduced to twins as compared to nonreduced twins the percentage of miscarriage was slightly higher, but not statistically significant $(7.6 \%$ compared to $6.9 \%, 0.07 \times 2$, $P$ 0.8). The median gestation at delivery was lower $(33.3 \pm 9.2$ compared to $35.67 \pm 5.84$ weeks, $2.26>2.0 \mathrm{t}, 0.05 \mathrm{P}$ ) and the

\footnotetext{
${ }^{1}$ Head and Director, ${ }^{2}$ Intern

1Department of Obstetrics and Gynecology, Shewale Hospital Ajanta Fertility Centre, Aurangabad, Maharashtra, India

${ }^{2}$ Department of Embryology, Shewale Hospital, Ajanta Fertility Centre, Aurangabad, Maharashtra, India
}

Corresponding Author: Anuradha R Shewale, Head and Director, Shewale Hospital, Ajanta Fertility Centre, Aurangabad Maharashtra, India, e-mail: shewale_10@yahoo.co.in median weight deficit was greater $(1.58 \pm 0.96$ compared to $1.92 \pm 0.89$ (4.04 >3.37 t, $0.001 \mathrm{P})$.

Keywords: Embryo reduction, Multifetal pregnancy, Transvaginal ultrasound-guided, Preterm delivery, Growth retardation.

How to cite this article: Shewale AR, Shewale B. Preterm Delivery and Growth Restriction in Multifetal Pregnancies reduced to Twins: Case-Control Series. Int J Infertil Fetal Med 2014;5(2):40-43.

Source of support: Nil

Conflict of interest: None

Date of Received: 10-07-14

Date of Acceptance: 18-08-14

Date of Publication: May 2014

\section{INTRODUCTION}

An adverse consequence of the widespread introduction of assisted reproductive techniques has been an exponential increase in the prevalence of multifetal pregnancies. ${ }^{5}$ Such pregnancies are associated with increased risk of miscarriage and perinatal death. ${ }^{9}$ One of the options in the management of multifetal pregnancies is embryo reduction to twins which is associated with a reduction in the background risk of adverse pregnancy outcome. ${ }^{6}$ The aim of the study was to compare the gestation at delivery and birth weight of surviving twins following multifetal pregnancy reduction to those in a control group of dichorionic nonreduced twins.

Multiple pregnancies constitute a common iatrogenic outcome of ovarian stimulation with fertility drugs and assisted reproductive technology. The prevalence of multiple pregnancies in these situations has shown an exponential increase during the past two decades. Moreover, the incidence of multiple pregnancies following assisted reproduction treatment is also directly related to the number of transferred embryos.

Multiple pregnancies have a higher likelihood of obstetric and perinatal morbidity and mortality, especially when more than two fetuses are present.

Though first-trimester embryo reduction may be an effective and safe option this study aims at establishing increased rates of preterm delivery and growth retardation in these patient. However, psychological, sociological and ethical considerations should be taken into account when measuring the cost-effectiveness of this rescue technique. The individualization of each clinical condition, as well as meticulous selection of the number of transferred embryos, should be routine procedure in assisted reproduction treatment units. 
The most likely cause of pregnancy loss and severe preterm delivery in multifetal pregnancies following reduction is the development of an inflammatory response to the resorbing dead fetoplacental tissue with subsequent release of cytokines and stimulation of prostaglandins. High concentrations of $\alpha$-fetoprotein ( $\alpha$-FP) are found in the amniotic fluid of twin pregnancy after the spontaneous death of one of the fetuses ${ }^{3,13}$ and in multifetal pregnancies after reduction. ${ }^{7,8}$ Similarly, both spontaneous fetal death ${ }^{12,13}$ and disruption in the fetoplacental barrier ${ }^{4}$ are associated with high maternal serum $\alpha$-FP levels. We have previously shown that, in the multifetal pregnancies, following the iatrogenic death of fetuses there is an increase in maternal serum $\alpha$-FP concentration is proportional to the amount of dead fetoplacental tissue and this increase persists for several months following the procedure. ${ }^{1}$ Multifetal pregnancies reduction to twins is associated with a relative decrease in maternal serum concentrations of placental hormones, such as human chorionic gonadotropin, progesterone and estriol, ${ }^{8}$ which occurs within 2 weeks of the reduction and persists for at least 3 months.

In multifetal pregnancies reduced to twins the birth weight for gestation was smaller than in nonreduced twins. A possible explanation for these findings is that in the human, the maximum capacity of the endometrium/decidua to maintain a pregnancy is achieved with twins; in multifetal pregnancies there is crowding and each fetal-placental-endometrial unit has less potential for growth and development than in twin pregnancies. In multifetal pregnancies reduced to twins, maternal serum concentrations of IGFBP-1 and PP14 decrease to values characteristic of singleton rather than nonreduced twins pregnancies. ${ }^{2}$

\section{STUDY OBJECTIVES}

1. To study the perinatal outcome of embryo reduction in multifetal pregnancy in patients undergoing ART.

2. To compare the incidence of preterm delivery and growth restriction of reduced multifetal pregnancies with that of matched control group.

\section{PATIENTS AND METHODS}

1. Study design

2. Study procedures

3. Statistical procedures

Between January 2012 and December 2013, 26 procedures and their outcomes were recorded in women with multiple pregnancy (24 triplets, 2 quadruplets). These pregnancies resulted from 8 IVF embryo transfers, 3 intrauterine inseminations (IUI), 15 intracytoplasmic sperm injections (ICSI). Each patient was informed about the potential risks of the technique, and written consent was obtained before the surgical procedure was carried out.

A routine vaginal ultrasound, confirming the number of embryos with heart activity, was performed before surgery. Median (range) gestational age at reduction was 7 to 9 weeks, median (range) number of fetuses before reduction was 3 to 4 . Under general anesthesia using propofol $10 \%$, surgical field cleaning was carried out with povidone iodine. The embryos were then visualized using a $7.5 \mathrm{MHz}$ transvaginal ultrasound transducer (GE LOGIC BOOK XP) in order to verify their number, ${ }^{11}$ position, size and heart activity. The smallest embryo and/or that located closest to the fundus of the uterus was selected for embryo reduction. This protocol reduced the technical difficulties of the procedure, and avoided the greater bleeding or infection risks resulting from the selection of a sac located near the cervix. The same $30 \times 1.8 \mathrm{~mm}$ outer diameter needle used for the ovarian follicular puncture (Oocyte Puncture Set; swemed) was inserted through a guide attached to the transvaginal ultrasound transducer. Exact alignment between the needle and the ultrasound screen guide was necessary to perform the procedure with accuracy. The surgeon started the embryo heart puncture, $2 \mathrm{ml} \mathrm{1:1} \mathrm{KCl}$ solution injected intracardiac until asystolia was confirmed. Without aspirating embryo tissue or amniotic fluid, it was possible to visualize adequately the embryo throughout the entire procedure. Fetal heart rate in the viable fetuses was normal. All embryo reductions were carried out by the same surgeon (AR Shewale).

Women were discharged from the clinic after a bed rest and an average observation period of 45 minutes. Thereafter, the following treatments were administered: $750 \mathrm{mg}$ of prophylactic amoxycillin every 8 hours for 5 days, an analgesic such as tramadol and, when indicated, Rh-negative immune globulin prophylaxis. The first ultrasound was carried out after 1 week. All patients underwent subsequent prenatal routine follow-up.

The control group included 43 assisted reproduction patients with nonreduced twin pregnancies performed over the same time period as the studied embryo reduction group. A stratified random selection was carried out according to the number of sacs visualized (two).

Data were expressed as mean $\pm 2 \mathrm{SD}$. For statistical comparison, analysis of variance (ANOVA) was used to compare mean patient age, birth weight, and mean gestational age at delivery. Chi-square and Fisher's exact tests were used to examine the significance of differences between the group undergoing multifetal pregnancy reduction and the normal dichorionic twins for pregnancy outcome, gestational age at delivery and birth weight. A p-value of 0.05 was considered to be statistically significant. 


\section{RESULTS}

The average patient was aged cases $28.6 \pm 5.56$ years, control $28.25 \pm 4.98$. Of the 26 embryo reduction procedures, were performed between the seventh and ninth weeks of gestation; women underwent reduction to twins. The average time required for the embryo reduction was $15 \pm 5$ minute per sec. Nearly all embryo reduction procedures were successfully performed in a single session, and only one case had to be repeated a week later. No complications occurred due to the surgery or the use of general anesthesia.

The incidence of early postoperative complications, defined as observed complications between 24 hours and 14 days after the embryo reduction, are shown in Table 1. After surgery, each patient took oral antibiotics for 7 days, commencing on the day of surgery (in cefotaxime 1 gm 12 hourly on day of procedure, oral cefalexin $500 \mathrm{mg} 12$ hourly for 5 days). No maternal morbidity was registered in the subsequent follow-up.

Both twins were live and survived the neonatal period in $18(69.23 \%)$ cases. In $2(7.6 \%)$ pregnancies, there was miscarriage of both fetuses before 24 weeks of gestation, in $7(26.9 \%)$ cases, there was intrauterine or neonatal death of one of the fetuses.

The preterm delivery rate (defined as fetuses delivered before 37 weeks) in twin pregnancies was 53.8\% $(n=14)$, with a severe preterm rate (defined as fetuses delivered before 32 weeks) of $23.07 \%(n=6)$. One case $(1.92 \%)$ of stillbirth occurred. The perinatal mortality rate was $13.46 \%$ (6 newborns, and a 33-week stillbirth due to placental insufficiency), mainly due to severe preterm labor. The latter group included no registered cases of newborns with congenital malformations. A total of 24 patients $(92.3 \%)$ with twin pregnancies took home at least one baby, while $18(69.23 \%)$ of these took both babies home.

The incidence of early complications and neonatal outcomes in reduced pregnancies was compared to that of the control group (Table 2).

In two of the 26 multifetal pregnancies reduced to twins there was miscarriage of both fetuses before 24 weeks of gestation the median interval between reduction and multifetal loss was 5 weeks.

In pregnancy reduced to twins as compared to non reduced twins the percentage of miscarriage was slightly higher, but not statistically significant $(7.6 \%$ compared to $6.9 \%, 0.07 \times 2$, $\mathrm{P} 0.8)$. The median gestation at delivery was lower (33.3 \pm 9.2 compared to $35.67 \pm 5.84$ weeks, $2.26>2.0$ t, $0.05 \mathrm{P}$ ) (Graph 1) and the median weight deficit was greater $(1.58 \pm 0.96$ compared to $1.92 \pm 0.89(4.04>3.37 \mathrm{t}, 0.001 \mathrm{P})($ Graph 2$)$.

\section{DISCUSSION}

The data presented in this study demonstrate that in multifetal pregnancies reduced to twins, in comparison to normal dichorionic twins, there is a slight increase in risk of miscarriage before 24 weeks of gestation, an increased probability of severe preterm delivery before 33 weeks and a reduction in birth weight for gestation.

The present study concludes that TVS guided multifetal reduction to non reduced twins (all ART conceptions) has more preterm deliveries.

Miscarriage rate was higher in study group $7.6 \%$ as compared to control group $6.9 \%$ but it was not statistically significant. In two multifetal pregnancies from the study group there were miscarriages of both fetuses before 24 weeks and none in control group.

Number of preterm deliveries 14 out of $26(53.8 \%)$ in study group as compared to 12 out of $43(27.9 \%)$ in control group. Statistically significant increase in preterm deliveries observed in study group when compared with control.

Number of neonatal deaths 6 out of $26(23.07 \%)$ in study group and 2 out of $43(4.65 \%)$ in control group. Neonatal weight in study group $1.58 \pm 0.96$ as compared to that in controls $1.92 \pm 0.89$. Statistically significant decrease in neonatal weight in study group when compared with control group.

Similar results have been obtained in the following studies:

'Twin gestations resulting from multifetal reduction are at increased risk for preterm birth, fetal growth restriction,

Table 1: Early postoperative complications in patients undergoing embryo reduction ${ }^{10}$

\begin{tabular}{ll}
\hline Complication/outcome & $n=26$ \\
\hline Spotting $(\mathrm{n})$ & 05 \\
Miscarriage $(\mathrm{n})$ & 02 \\
Vanishing embryo $(\mathrm{n})^{\text {Malformation }(\mathrm{n})^{11}}$ & 00 \\
Chorioamnionitis $(\mathrm{n})_{\text {Stillbirth }(\mathrm{n})}$ & 00 \\
Neonatal death ( $\mathrm{n})$ & 00 \\
Gestational age at delivery (weeks) & 06 \\
Average birth weight (kg) & $33.3 \pm 9.2$ \\
Patients with baby at home (n) & $1.58 \pm 0.96$ \\
& $24($ single baby $=6$, \\
& twins $=18)$ \\
\hline
\end{tabular}

Table 2: Comparison of reduced pregnancies with their control group (matched for age, method of conception)

\begin{tabular}{lll}
\hline Complication/outcome & Reduced $(n=26)$ & Control $(n=43)$ \\
\hline Miscarriage & 02 & 03 \\
Placental abruption & 02 & 00 \\
Preterm deliveries & 14 & 12 \\
$\begin{array}{l}\text { Malformation } \\
\text { Neonatal death }\end{array}$ & 00 & 00 \\
$\begin{array}{l}\text { (as per number of } \\
\text { neonates that died) }\end{array}$ & 06 & 02 \\
$\begin{array}{l}\text { Gestational age at } \\
\text { delivery (weeks) }\end{array}$ & $33.3 \pm 9.2$ & $35.67 \pm 5.84$ \\
$\begin{array}{l}\text { Birth weight }(\mathrm{kg}) \\
\begin{array}{l}\text { Patients with baby } \\
\text { at home }\end{array}\end{array}$ & $1.58 \pm 0.96$ & $1.92 \pm 0.89$ \\
\hline
\end{tabular}




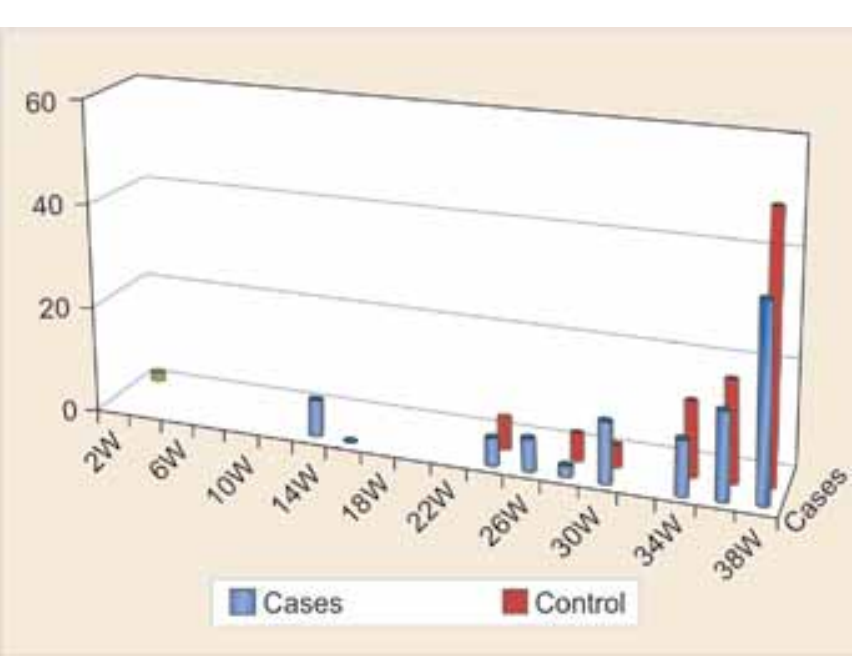

Graph 1: Gestational age distribution at delivery in multifetal pregnancies reduced to twins $(33.3 \pm 9.2$ weeks) compared to non reduced dichorionic twins ( $35.67 \pm 5.84$ weeks)

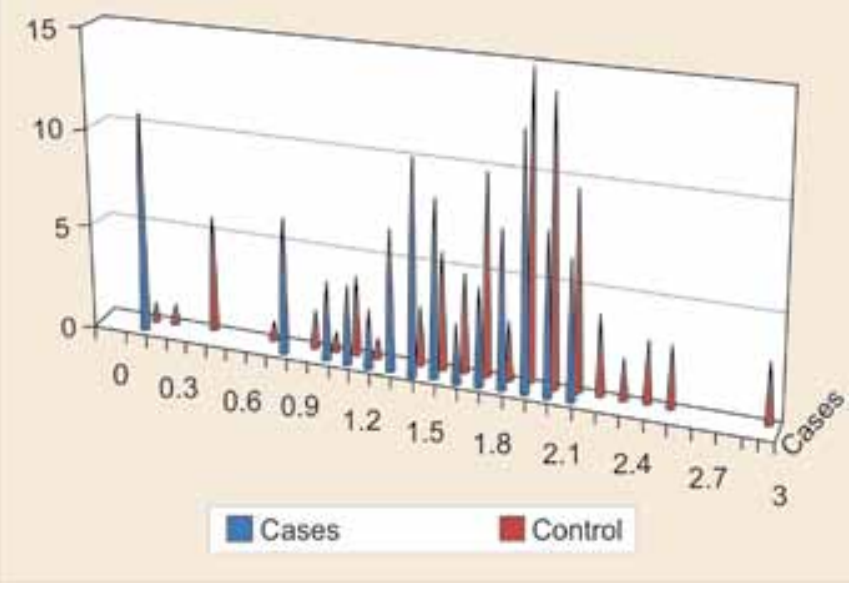

Graph 2: Birth weight distribution at delivery in multifetal pregnancies reduced to twins $(1.58 \pm 0.96 \mathrm{~kg})$ compared to non reduced dichorionic twins ${ }^{14}(1.92 \pm 0.89 \mathrm{~kg})$

and discordancy when compared with fertility therapyderived, nonreduced twins.' Multifetal reduction increases the risk of preterm delivery and fetal growth restriction in twins: a case-control study. ${ }^{15}$

Serious attention should be paid to reducing the number of higher-order multiple pregnancies resulting from infertility therapy. In the meantime, when three or more fetuses have been conceived, multifetal pregnancy reduction offers a reasonable option to patients whose only choices in the past were either to accept the risk of delivering extremely prematurely or to terminate the entire pregnancy. ${ }^{16}$

To conclude, multifetal reduction is not an answer to multifetal pregnancy due to $>2$ embryo transfers per cycle. The complications in reduced twins (preterm delivery and growth restriction) are higher than their nonreduced counterparts. Hence, soft protocol for IUI cycles and single blastocyst transfer for IVF and ICSI cycles is ideal.

\section{REFERENCES}

1. Abbas A, Johnson M, Bersinger N, Nicolaides K. Maternal alpha-fetoprotein levels in multiple pregnancies. Br J Obstet Gynaecol 1994 Feb;101(2):156-158.

2. Abbas A, Johnson M, Chard T, Nicolaides KH. Maternal plasma concentrations of insulin-like growth factor binding protein-1 and placental protein 14 in multifetal pregnancies before and after fetal reduction. Hum Reprod 1995;10:207-210.

3. Bass HN, Oliver JB, Srinivasan M, Petrucha R, Ng W, Lee JE. Persistently elevated AFP and AChE in amniotic fluid from a normal fetus following the demise of its twin. Prenat Diagn 1986 Jan-Feb;6(1):33-35.

4. Blakemore KJ, Baumgarten A, Schoenfeld-Dimaio M, Hobbins JC, Mason EA, Mahoney MJ. Rise in maternal serum alphafetoprotein concentration after chorionic villous sampling and the possibility of isoimmunization. Am J Obstet Gynecol 1986 Nov;155(5):988-993.

5. Botting BJ, Davis IM, Macfarlane AJ. Recent trends in the incidence of multiple births and associated mortality. Arch Dis Child 1987 Sep;62(9):941-950.

6. Evans MI, Dommergues M, Wapner RJ, Lynch L, Dumez Y, Goldberg JD. Efficacy of transabdominal multifetal pregnancy reduction: collaborative experience among the world largest centres. Obstet Gynecol 1998;82:61-66.

7. Grau P, Robinson L, Tabsh K, Crandall BF. Elevated maternal serum alpha-fetoprotein and amniotic fluid alpha-fetoprotein after multifetal pregnancy reduction. Obstet Gynecol 1990 Dec; 76(6):1042-1045.

8. Johnson MR, Abbas A, Nicolaides KH. Maternal plasma levels of human chorionic gonadotropin, oestradiol and progesterone before and after fetal reduction. J Endocrinol 1994 Nov;143(2): 309-312.

9. Kiely J, Kleinman JC, Kiely M. Triplets and higher-order multiple births. Time trends and infant mortality. Am J Dis Child 1992 Jul;146(7):862-868.

10. Nicolaides K1, Brizot Mde L, Patel F, Snijders R. Comparison of chorionic villous sampling and amniocentesis for fetal karyotyping at 10-13 weeks' gestation. Lancet 1994 Aug 13; 344(8920): 435-439.

11. Sepulveda W, Sebire NJ, Hughes K, Odibo A, Nicolaides KH. The lambda sign at 10-14 weeks of gestation as a predictor of chorionicity in twin pregnancies. Ultrasound Obstet Gynecol 1996 Jun;7(6):421-423.

12. Seppala M, Ruoslahti E. Alpha fetoprotein: physiology and pathology during pregnancy and application to antenatal diagnosis. J Perinat Med 1973;1(2):104-113.

13. Streit JA1, Penick GD, Williamson RA, Weiner CP, Benda JA. Prolonged elevation of alpha-fetoprotein and detectable acetylcholinesterase after death of an anomalous twin fetus. Prenat Diagn 1989 Jan;9(1):1-6.

14. Yudkin PL, Aboualfa M, Eyre JA, Redman CW, Wilkinson AR. New birth weight and head circumference centiles for gestational ages 22 to 42 weeks. Early Human Dev 1987 Jan;15(1):45-52.

15. Silver RK, Helfand BT, Russell TL, Ragin A, Sholl JS, MacGregor SN. Multifetal reduction increases the risk of preterm delivery and fetal growth restriction in twins: a case-control study. Fertil Steril 1997 Jan;67(1):30-33.

16. Berkowitz RL, Lynch L, Stone J, Alvarez M. The current status of multifetal pregnancy reduction. Am J Obstet Gynecol 1996 Apr;174(4):1265-1272. 